\title{
The specifics of the evaluative metaphor in English (based on the texts of art discourse)
}

\author{
Adilkhan Shorabek - Bakiza Pazilova - Gulzhan Manapova - Zhanna \\ Tolysbayeva - Nurlan Mansurov - Roman Kralik
}

DOI: 10.18355/XL.2021.14.02.18

\begin{abstract}
This article deals with a comprehensive description of the evaluativeness of metaphors in modern English. The evaluation criteria underlying the evaluability of metaphors are determined, variations as an object of evaluation and an agent as a donor of evaluation in the semantic structure of metaphors are considered, axiological types of lexical and semantic groups of metaphors are differentiated, and the means and conditions for varying the evaluability of metaphors are systematized. This research paper depicts the pragmatic relevance of the evaluative metaphor and represents the typology of demographic, socio-cultural, and national-cultural signs of the evaluability of metaphors. The axiological status of the metaphor is established by a comprehensive description of the semantic, syntactic, pragmatic, and sociolinguistic features of the evaluation of the metaphor in modern English.

The specificity of evaluativeness as a component of meaning in the semantics of a metaphor is determined. The results of the study of metaphor are presented in many linguistic works. However, some provisions concerning the functioning of the metaphor and its ability to reflect the individual author's worldview have not yet been sufficiently studied. To study the metaphor as an assistant to the creation of images that express the author's attitude to something and its social, political, philosophical position, and as a means by which we know the world around us, it is necessary to examine the existing theoretical material and subsequent analyses of specific cases of using the metaphor.
\end{abstract}

Key words: metaphor, evaluative metaphor, specificity, semantics, semantic criteria

\section{Introduction}

In the process of cognition of the surrounding reality, a person determines his attitude to the world by evaluating events, phenomena, and facts. In this regard, the problem of evaluation attracts the attention of researchers in the field of philosophy, logic, psychology, and linguistics.

Language has different ways of expressing evaluation. A metaphor in a person's thesaurus is an element of their evaluative activity since any metaphor has an evaluative meaning. Attempts to create a theory of metaphor were made in antiquity (Aristotle, Quintilian, Cicero, Rouillac, etc.). Despite the close attention to the problems of metaphor in general, the specifics of the axiological aspect of metaphor in modern English have not yet found a complete systematization.

Today, linguists are increasingly turning their attention to how a person evaluates the phenomena of their reality. Evaluation, which is an objective and at the same time subjective factor of a person's attitude to the surrounding world, is the subject of study of such sciences as psychology, sociology, and philosophy. Evaluation, implemented verbally, is mainly studied by such sciences as linguistics, sociolinguistics, and psycholinguistics. In addition, linguistic pragmatics deals with the study of the speaker's attitude (especially evaluative) to what he reports. Despite the fact that as a means of expressing the author's assessment, the metaphor has been studied by many scientists, this phenomenon is not sufficiently studied. Metaphor plays an essential role in the artistic style of speech and has a high significance for the

XLinguae, Volume 14 Issue 2, April 2021, ISSN 1337-8384, eISSN 2453-711X 
language as a whole. Therefore, the prospect of its further study can be determined by the theoretical and practical needs during training (Ageev, 2002).

Evaluativeness plays a role in the semantics of metaphors, the need to systematize the evaluation criteria that underlie the evaluativeness of metaphors of different parts of the river, the need for further research on the variation of the evaluative component of meaning in the semantics of metaphors and the axiological specificity of lexicalsemantic groups of metaphors, and the lack of knowledge of the pragmatic and sociolinguistic aspects of the evaluativeness of metaphors.

The semantics of the word implies the division of evaluativeness by type into zero or neutral, positive or reclamation, and negative or pejorative. In addition, evaluativeness can be divided by type into rational and emotional. N. A. Lukyanova notes that such divisions have highly conditional boundaries since human consciousness's intellectual and sensory activities are also differentiated relatively (Lukyanova, 1991).

Rational evaluation is based on information concerning the objectively inherent properties in the object of evaluation and can express their compliance with certain norms. Thus, rational evaluation can be attributed to the norm and defined as neutral (Buzadzhi, 2009).

Metaphors that contain a rational evaluative component of meaning include metaphors-terms, erased metaphors, and metaphors with a neutral meaning that characterize a person's appearance and profession - for example, carrot - red-haired, pill-doctor (Vezhbitskaya, 1999).

Properties that are not objectively inherent in a particular object of evaluation are often fixed by emotional evaluation. In this case, the object considered on the rating scale "good" / "bad" will be assigned to a particular category based not on general criteria but on the emotions caused by the object of evaluation. For example, the metaphor "bastard" can be used in relation to any object that causes negative emotions. In this case, the emotional evaluation will replace the meaning of "illegitimate," that is, the denotative meaning of this word (Gibatova, 1996).

The definition of an evaluative sign in the structure of an evaluative act may be due to the presence of evaluative features of a word in a context or situation that implies an interaction between the semantics of a word and the semantics of an utterance. In some cases, evaluativeness can be included in the semantics of the units that make up the structure of the act of evaluation, but it can also act as a potential component of these units that appears in a particular text. A good example is the combination type that we see in the metaphor 'crooked mouth' (crooked mouth). If there is a negative rating, then such a combination as paleface (pale face) in different contexts will be accompanied by a different rating sign.

In addition, the semantics of the word contains an evaluation sign that is already fixed. For example, such words as clever (smart), admirable (wonderful), honest (honest) contain a positive rating sign; and the words: dirty (indecent), awful (terrible), etc. - negative. Such adjectives of evaluation are very important in the evaluation process, as they help identify the evaluation sign of lexical units that can be combined with each other. The following metaphors can be used as examples: dirty dog, but clever dog (clever girl).

When studying the structure of the assessment act, the human factor is taken into account since the language personality always acts as the subject of the assessment, and in most cases, the person will act as the object of the assessment. Human communication is characterized by the designation of the relationship to the physical and mental properties of a person and himself, which is more characteristic than the expression of the relationship to any objects. Thus, it can be argued that the uniqueness of the assessment can be manifested in anthropometricity, which is a comeasurement of the object of assessment and a certain standard that highlights the properties that a person attributes to this standard (Gritsenko, 2009). 
Also, according to V. N. Telia, anthropometricity is represented by the ability to comprehend one entity as if it were a likeness of another; that is, anthropometricity helps to measure these entities, taking into account the entire scale of a person's knowledge and ideas, as well as his system of national and cultural values and stereotypes. Thus, the anthropometric approach directs its attention to a person who is characterized in such aspects as social, emotional, pragmatic, etc. (Telia, 2009)

A person is inherent in evaluating himself and the reality around him within a particular thesaurus, so the metaphor acts here as a necessary tool. When considering the features of the evaluative semantics of metaphor, it should be noted that the theory of metaphor contains traditional statements concerning the semantic ambiguity of metaphor, its contextual environment, and regularity, certain semantic classes of words that are able to develop the meanings of images, as well as such objective features of metaphor as syntactic and morphological, metaphorical abstraction, expressiveness, and evaluativeness.

Semantic ambiguity, which is an invariant of all created theories on metaphor, can be determined by the heterogeneity and hypothetical nature of various objects expressed in metaphor using the synthesis of two opposite meanings: "similar" and "not." According to the linguistic tradition, the implementation of metaphorical semantic ambiguity is correlated with the context, which is the key to understanding the meaning of the phenomenon under study. Thus, to consider evaluativeness as a component of meaning in the semantics of a metaphor, it is necessary to take into account the semantics of an individual word and the semantics of the given word in context. A metaphor can be considered linguistic if it becomes a ready-made "block" and occurs in various new contexts (Guillaume, 1992).

One of the properties of metaphor is to identify "one's own" through "someone else's," the individual through the general, anomalies through the norm. The process of evaluating an individual with the help of a metaphor is carried out through normative signs and is accompanied by the creation of a personal image. This results in the creation of individual characteristics that pertain to the basis for stereotyping, with which one can clarify thinking and reduce a large amount of information during the process of mastering reality. Due to the stereotyping of features in the semantics of metaphor, so-called "precedent" metaphors appear, which are standard tools used in the assessment of any well-known facts, events, or relationships, and are located in the fund of mandatory knowledge for every native speaker. The metaphor also has an internal form, which, due to the presence of a figurative representation of the stereotype, rather than its direct designation, can be defined as a quasi-stereotype.

The evaluativeness of a metaphor has both structuralistic and activity-based characteristics. Evaluativeness is a component of the structure of metaphorical meaning and, at the same time, acts as an axiological mechanism of human communicative activity, which is characterized in two aspects: pragmatic and sociocultural. Much attention in linguistics is paid to the semantic structure of the word, the identification of the types of meanings of words and the criteria for their differentiation, the ways of changing and developing the meanings of words (Gladkova, 2007)

Perceiving the phenomena of reality, a person expresses his non-neutral attitude to it by evaluating: "good" - "bad," "good" - "bad." Being expressed by language means, the evaluation is implemented in the component of the word meaning, which is called evaluativeness.

Following N. A. Lukyanova, we recognize that there are two types of evaluativeness: 1. rational (intellectual) - assessment of the surrounding reality (subjects, objects, qualities, phenomena)

2. emotional - passed through the prism of the human psyche (Lukyanova, 1991).

XLinguae, Volume 14 Issue 2, April 2021, ISSN 1337-8384, eISSN 2453-711X 
The emotional evaluativeness of the metaphor is the result of the actualization of the evaluative semes of the connotative aspect of the meaning of the word. Thus, the negative emotional evaluation of the metaphor "weed," "skinny, lanky man," is the result of the actualization of the connotative semes of the original meaning of the word - "weed."

The rational evaluativeness of the metaphor is the result of the actualization of the evaluative semes of the denotative aspect of the meaning of the word. Thus, the rational evaluation of the metaphor "pill" "doctor" is the result of the actualization of the differential denotative semes of the original meaning of the word "pill."

The question of the relationship of evaluativeness, emotivity, intensity, and stylistic component in the structure of the meaning of a word has been facing lexicologists for a long time. These components of meaning are integrated into the structure of the connotative aspect of the meaning of the word, but each of them has a qualitative peculiarity.

Evaluativeness, along with other components of the connotative aspect of the meaning of a word, is a means of achieving the expressiveness of the word. Expressiveness is understood as "a set of semantic and stylistic features of a language unit that ensure its ability to act in a communicative act as a means of subjective expression of the speaker's attitude to the content or to the addressee of speech."

In our opinion, expressiveness in the structure of the meaning of the word is appropriate when considering a component of the pragmatic aspect of the meaning of the word since it arises as a result of the selection and use of words only in the process of communication. Pragmatics includes both methods of influence that cause emotional reactions in the addressee, which characterizes expressiveness, and all means of influence that are associated with goal-setting language activity. At the same time, it should be recognized that the connotative aspect of the meaning of the word is closely related to the pragmatic aspect since both of them characterize the communicative situation, the participants in communication, and their attitude to the object.

Emotions are displayed in the structure of the meaning of the word in the component called emotivity. According to M. S. Retunskaya, emotivity is a linguistic representation of emotion by means of different levels of language, including lexical, which is not only associated with the expression of the emotional and evaluative attitude of the sender of the speech but also aimed at creating an emotional resonance in the listener.

M. S. Retunskaya points out that the evaluative vocabulary contains in its meaning information about the emotional attitude to the designated object or phenomenon. Emotional-evaluative information is understood as an assessment of the surrounding reality, presented as a positive emotional assessment and its modifications (approval, affectionate attitude, admiration, etc.) and a negative emotional assessment and its modifications (disapproval, neglect, contempt, rude and soft ridicule) (Retunskaya, 2007).

Evaluativeness is a mandatory element of emotivity. A person's assessment of an object or phenomenon is often based on emotional experiences, but emotivity is not always a mandatory element of evaluativeness: the same word in different speech situations can express either only an emotion or an emotion and an assessment at the same time (Donskova, 1987)

Metaphor is a universal mechanism in the formation of emotional-evaluative categories. In the semantic structure of a metaphor, the presence of positive or negative evaluativeness always indicates the presence of emotivity. The metaphor contains not only a figurative representation and information about the assessment, but also the expression of a certain feeling-attitude, conscious emotion, such as 
contempt, neglect, or, conversely, respect, admiration, etc., as well as stylistic coloring. The integration of evaluativeness and emotivity in the semantics of metaphor makes metaphor an expressive means.

The evaluativeness of the metaphor implements the evaluative relations of the language community to the concept or object correlated with the metaphor according to the type "good / bad" in the range of the scale from "very good" to "very bad." In the most general terms, we can say that "good" is something that contributes to the satisfaction of the needs of the individual, the community, and humanity as a whole, including aesthetic and moral-ethical needs, which is favorable in moral and physical terms. Likewise, "bad" is everything that is imperfect, erroneous, harmful to the individual and the community, is in contradiction with aesthetic and moral-ethical norms.

The antonymic nature of the evaluation processes is based on the juxtaposition of intuitively perceived positive and negative qualities of the "good / bad" type. The antonymic nature of the assessment is the basis of a person's knowledge of the surrounding reality since the assessment determines the value of an object, action, or feature in the world picture of a given society.

The evaluation features of the qualification scale are divided by the norm zone. In the positive part of the scale, the presence of a certain sign in relation to the norm is stated, which is considered as good; in the negative part of the scale, the sign is stated as bad:

The norm assumes the balance of the features on the scale and correlates with the stereotypical ideas about the average number of features that a given object should have. The norm is a reflection of the complex interaction of the universal human value system, the value system of the author of the assessment, and the value systems of the social groups (regional, age, professional, religious, etc.) with which the author of the assessment is associated. Deviations from the norm imply positive or negative signs of evaluation.

The evaluation features that determine the meaning of the axiological predicates "good / bad" are included in the semantics of the original word and are updated in the semantics of the metaphor.

In most modern European cultures, words with negative evaluative features predominate. The psychological explanation of the reasons for this asymmetry may lie in the fact that the negative aspects of life are perceived by a person much more acutely than the positive factors, which are considered as natural, normal, and therefore less emotional. V. N. Telia notes that human morality tends to be stigmatized rather than "raised to heaven." It is possible that it was the biblical culture that contributed to this state of affairs, for it is said: "Do not create an idol for yourself" (Telia, 2009).

The definition of the evaluation sign in the structure of the evaluation act is determined by the contextual or situational actualization of the evaluation features of the word, which implies the interaction of the semantics of the word and the semantics of the utterance. Evaluativeness is, in some cases, included in the semantics of the units that make up the structure of the act of evaluation. In other cases, it can be considered as their potential component, which is induced in a certain text. So, if the combination of the crooked mouth type "crooked mouth" carries a negative rating, then the combination of the high forehead type "high forehead," pale face "pale face" may have a different rating sign in different contexts (Lukyanova, 1991).

On the other hand, the semantics of a word often define a fixed evaluation sign:

- clever "smart"

- admirable "wonderful"

XLinguae, Volume 14 Issue 2, April 2021, ISSN 1337-8384, eISSN 2453-711X 
- charming "cute"

- honest "fair"

- dirty "indecent"

- awful "terrible"

- false "fake," etc. (negative rating sign).

These evaluative adjectives play an important role in the act of evaluation since they allow us to identify the sign of evaluation of combined lexical units in particular metaphors: cf. dirty dog "scoundrel," but clever dog "clever girl"; grave owl "dissatisfied person," but solemn owl "wise man."

The study of the structure of the act of evaluation involves taking into account the human factor, since the subject of evaluation is always a person as a language personality, and the object of evaluation is mainly a person. The designation of the relationship to a person and his physical and mental properties is more characteristic of human communication than the statement of the relationship to objects.

The peculiarity of evaluation is manifested in the form of anthropometricity, i.e., "in such a co-measurement of the object of evaluation and a certain standard, in which the properties attributed by a person to this standard are put forward to the fore." V. N. Telia defines anthropometricity as "the ability to think of one entity as if it were similar to another, and this means to co-measure them in accordance with the actual human scale of knowledge and ideas, and at the same time with the system of national and cultural values and stereotypes," in other words, "the awareness of a person as a measure of all things."

Thus, the anthropometric approach puts the focus on a person characterized in social, emotional, pragmatic, and other aspects.

A person evaluates himself and the reality around him within the framework of his thesaurus, and a metaphor in this practice is a necessary tool. Therefore, it seems appropriate to consider the ontology of the metaphor and the features of its evaluative semantics (Johnson, 1990).

\section{Discussion}

What follows is an analysis of evaluative metaphors in the stories of Jeffrey Archer. The material for this analysis consisted of ten stories: The Coup; the first Miracle; One Night Stand; One Hundred Runs; Henry starts to stutter; A Matter of Principle; The Luncheon; Chinese Statuette; Real Gentleman; Just Good Friends from the collection "Short Stories" by Geoffrey Archer - a modern English writer and politician.

In the course of the analysis, evaluative metaphors were distributed in Table 1 according to the types of their evaluativeness. 
Table 1 Metaphors of various types of evaluativeness in the stories of Jeffrey Archer

\begin{tabular}{|c|c|c|}
\hline Type & Rationale & emotional \\
\hline $\begin{array}{l}\text { Positive } \\
\text { (reclamation) }\end{array}$ & - & $\begin{array}{l}\text { 1) I will do anything for you, my } \\
\text { princess. } \\
\text { 2) I'll be soon, my flower. } \\
\text { 3) She was a ripe peach to him, so he } \\
\text { couldn't wait any longer. }\end{array}$ \\
\hline $\begin{array}{l}\text { Negative } \\
\text { (pejorative) }\end{array}$ & $\begin{array}{l}\text { 1) They lived with the } \\
\text { trash there. } \\
\text { 2) The first signs of a } \\
\text { broken marriage } \\
\text { came when the } \\
\text { Department of } \\
\text { Employment } \\
\text { announced that } \\
\text { inflation had taken an } \\
\text { upturn for the first } \\
\text { time in nine months. }\end{array}$ & $\begin{array}{l}\text { 1) She was a ghost at our party. 2) ... } \\
\text { but he loved that intelligent insect. } \\
\text { 3) I shall sue the bastard. } \\
\text { 4) The final shortlist included two } \\
\text { clever clogs from London - one of } \\
\text { whom later served in a Macmillan } \\
\text { cabinet - and the local boy, Ted Barker. } \\
\text { 5) This child is a pig and a beast. } \\
\text { 6) The witch's eyes were sparkling. } \\
\text { 7) You are the old cow! } \\
\text { 8) I know exactly where you stand, } \\
\text { Charles, and I feel confident that } \\
\text { whatever happens, you'll come through } \\
\text { your own mound of manure smelling of } \\
\text { roses. } \\
\text { 9) Why is he still looking at this bitch. } \\
\text { 10) Telex them back immediately and } \\
\text { inform them you're a chairman of the } \\
\text { greatest construction company in the } \\
\text { world, and they can roast in hell before } \\
\text { you agree to their pathetic terms. } \\
\text { 11) I can't see them together. I can't } \\
\text { talk to her. I am a trapped hare } \\
\text { 12) The government is cutting their } \\
\text { throats with the wretched system; they } \\
\text { can't expect unskilled men, black or } \\
\text { white, to become experienced engineers } \\
\text { overnight. } \\
\text { 13) That rest was to last a complete } \\
\text { week before Henry rolled a thorny } \\
\text { thundercloud across the clear blue } \\
\text { summer sky by announcing he would } \\
\text { contest the leadership of the Labour } \\
\text { party at the October conference. } \\
\text { 14) And then you became a hunted } \\
\text { animal. } \\
\text { 15) Septimus not only liked his } \\
\text { lifestyle, but was distressed if for any } \\
\text { reason, his routine met the slightest } \\
\text { interference. }\end{array}$ \\
\hline $\begin{array}{l}\text { Neutral } \\
\text { (zero) }\end{array}$ & $\begin{array}{l}\text { 1) He was a young } \\
\text { bull with little brain. }\end{array}$ & $\begin{array}{l}\text { 1) He is just a jumping bean. } \\
\text { 2) "Have you been to London lately?" I }\end{array}$ \\
\hline
\end{tabular}

XLinguae, Volume 14 Issue 2, April 2021, ISSN 1337-8384, eISSN 2453-711X 


\begin{tabular}{|l|l|l|}
\hline & $\begin{array}{l}\text { 2) His son is a hefty } \\
\text { legged giant. } \\
\text { 3) } \ldots \text { and then he saw } \\
\text { those old salts. } \\
\text { 4) That pill is coming } \\
\text { here. }\end{array}$ & $\begin{array}{l}\text { roared above the bubble. } \\
\text { 3) You should control your tongue, my } \\
\text { 4) This kitten was sleeping on his } \\
\text { shoulder ... }\end{array}$ \\
$\begin{array}{l}\text { 5) A fleet of six black } \\
\text { Mercedes drove up to } \\
\text { the side of the aircraft } \\
\text { and waited in a line } \\
\text { resembling a } \\
\text { landbound crocodile. } \\
\text { 6) After all, it was he } \\
\text { who had become the } \\
\text { instrument that was } \\
\text { going to keep me } \\
\text { from a lifetime spent } \\
\text { in prison. }\end{array}$ \\
\hline
\end{tabular}

As we can see in the stories selected by us for analysis, to express the individual author's assessment, Jeffrey Archer used substantive metaphors, one adjectival metaphor, and three verbal metaphors. This is because the noun has the highest degree of evaluativeness since it can contain many different lexical and semantic meanings, which provide the author with a wide range of concepts that can be used as a metaphor. According to the origin of the metaphors, nine zoomorphic metaphors were used (for example, cow, pig, bull), and three phytomorphic ones (flower, peach, bean). In addition, the writer used many language metaphors (for example, pill, bastard), as well as his own individual author's metaphors (for example, a fleet of six black Mercedeses).

The metaphors presented in the table were selected as evaluative ones due to the content of positive, negative, or neutral connotative meanings in their lexemes. For example, the lexeme "peach" contains such a value as "an exceptionally good or attractive person or thing." In turn, the semantics of the lexeme "attractive" has a positive evaluation sign, which means that this metaphor expresses a positive evaluation of the author. Such metaphors as - bitch, bastard, witch, cow, trash, broken - contain negative semantics in their lexical meanings. In addition, the evaluativeness and types of most metaphors were determined by analyzing a more detailed context (Archer, 2008).

Thus, based on the distribution of the metaphors we found by types and their evaluativeness, we can conclude that the author most often uses metaphors with evaluativeness. He also used neutral evaluativeness, with emotional, neutral evaluativeness, emotional, positive, rational, and negative metaphors.

\section{Conclusion}

When reading literary texts, the reader usually trusts the author, so a properly expressed author's assessment has a significant impact on the reader's attitude to the characters and events and on the perception of the work of art as a whole. In everyday communication, as well as in a literary text, we can observe the interaction of metaphorical and evaluative meaning. Statements that are based on a metaphor have the potential of evaluative statements. The context and the person who perceives the text affect the reading of positive and negative metaphorical expressions.

The score is a dynamic category that contains a duality. On the one hand, the assessment has subjectivity and is based on the value system of a person; on the other hand, the subject of the assessment depends on the social group and culture to which 
it belongs. It is influenced by various opinions, regulations, and values of a given society.

Evaluation always originates from the subject and depends on its value system and priorities. The subject of the assessment expresses its attitude according to special criteria. These criteria describe the subject of evaluation as a linguistic personality and as a carrier of a certain value system, which is a dynamic set of special characteristics determined by time, society, and culture. After analyzing the various definitions of metaphor, we came to the conclusion that this phenomenon is most often defined as a hidden comparison, which is carried out by transferring the name of one object to another object and thus reveals some important characteristic or feature of the second. With the help of a metaphor, we can turn our attention to the similarity between two or more objects, which we most often did not notice before. Metaphor is not able to express the subject openly; it only helps to look at it from a certain angle.

\section{Bibliographic references}

AGEEV, S. V. 2002. Metaphor as a factor in the pragmatics of speech communication: author's abstract. ... Candidate of Philological Sciences, S. V. Ageev. St. Petersburg, 200 р. УДК 802.0 - 08

APRESYAN, V. YU. 1993. Metaphor in the semantic representation of emotions, Questions of linguistics. In: Publishing house "Infra” M", 264 p. ДМ 212.009.11

ARCHER, J. 2008. 36 stories, TRANS. English V. L. Hopman. In: Zakharov, 630 p. ISBN 978-5-353-03597-8

ARCHER JEFFREY COLLECTED STORIES. 1999. London In: Harper Collins, 710 p. ISBN. 978-5-8159-0874-1.

TELIA, V.N. 2006. This is such phraseology. In: Science, 85 p. ISBN 978-5-317$05348-2$

BUZADZHI, D. M. - GUSEV, V. V. - LANCHIKOV, V. K. - PSURTSEV, D. V. 2009. Anew look at the classification of translation errors. - Moscow: All-Russian Translation Center, 109 p. ISBN 5-7754-0078-7.

DAVIDSON, D. 1990. What metaphors mean, D. Davidson, The theory of metaphor. In: Progress, 126 p. ISBN 5-01-001599-4

DOBROVOLSKY, D. O. 1997. National-cultural specificity in phraseology, D. O. Dobrovolsky, Questions of linguistics. In: Moscow, Prosveshchenie, 1997. - 48 p. ISBN 978-5-317-04681-1

DONSKOVA, O. A. 1987. Subjectivity and evaluativeness in the semantics of the word , O. A. Donskova, Questions of semantics of lexical units. In: Rus. yaz., 26 p. УДК 81'373.21:578.5(477.61)

DURCO, P. 2020. Phraseological constructions preposition + noun in German and Slovak. In: Vestnik Sankt-Petersburgskogo Universiteta, Yazyk I Literatura, vol. 17, n.2, pp.412-425.

GIBATOVA, G. F. 1996. Semantic category of evaluation and means of its expression in the modern Russian language, In: Prosveshchenie,56 p. Д 212.189.11

GUILLAUME, G. 1992. Principles of theoretical linguistics In: Iz-vo Mosk. unuvercity, 87 p. ISBN 5-354-00684-8.

GLADKOVA, S. YU. 2007. The category of emotional evaluation in communication, In: Prosveshchenie, УДК 81'42

GRITSENKO, E. S. 2009. Emotional-evaluative enantiosemia in spoken speech, Theory and practice of linguistic description of spoken speech. Gorky, pp. 14-21, 64 р. УДК 81'373.21:556.5(477.61)

JOHNSON, M. - LAKOFF, D. 1990. Metaphors by which we live, M. Johnson, D. Lakoff, Theory of metaphors. 213 p. ISBN 0-226-4680 1-1 
LUKYANOVA, N. 1991. And. Expressiveness in the system dictionary and speech/ the Human factor in language: Language mechanisms expressive. In: Nauka, pp. 157178. ISBN 978-5-502-00368-1

RETUNSKAYA, M.S. 2007. Pragmatic characteristics of emotional-ocular lectures in the language. Theory and the practice of linguistic description of the issue. science. tr. - Gorky, pp.99-108. 212.216.03

VEZHBITSKAYA, A. 1999. Lexical semantics in the cultural comparative aspect, Semantic universals and description of languages. 647 p. ISBN 5-7859-0032-7.

Words: 4882

Characters: 31084 (17,27 standard pages)

Shorabek Adilkhan

Zhurgenov Kazakh National Academy of Arts,

Panfilov street, 127,

050000, Almaty

Kazakhstan

Pazilova Bakiza

Kazakh National Women's teacher training university

Aiteke bi Street, 99

050000, Almaty

Kazakhstan

Manapova Gulzhan

Kazakh National Women's teacher training university

Aiteke bi Street, 99

050000, Almaty

Kazakhstan

zurazhan@mail.ru

Prof. Zhanna Tolysbayeva

Kazakh national academy of choreography,

9 Uly dala avenue

010000, Nur-Sultan

Kazahstan

Mansurov Nurlan

Khoja Akhmet Yassawi International Kazakh-Turkish University,

Sattarkhanov 29,

161200 Bekzat

Kazahstan

Prof. ThDr, Roman Kralik, PhD.

Russian language department

Medical Institute RUDN University,

Miklukho-Maklaya street, 6

117198 Moscow

Russia

roman.kralik73@gmail.com 